\title{
Employment Protection: The Case of Limited Enforceability
}

\author{
FLORIAN BAUMANN
}

CESIFO WORKING PAPER NO. 2346

CATEGORY 4: LABOUR MARKETS

JULY 2008
An electronic version of the paper may be downloaded
- from the SSRN website: www.SSRN.com
- from the RePEc website: - from the CESifo website:




\title{
Employment Protection: The Case of Limited Enforceability
}

\begin{abstract}
This paper shows that the effects of employment protection critically depend on its enforcement. For this purpose, we capture evasion of employment protection via market exit in a setting of monopolistic competition. We find that the number of firms entering the market depends on firing costs only in the case of imperfect enforcement of employment protection. Furthermore, the possibility to circumvent firing restrictions by exiting the market mitigates the adverse efficiency effects of employment protection and can reverse the sign of the change in employment associated with an increase in firing costs.
\end{abstract}

JEL Code: J63, J65, L13.

Keywords: employment protection, evasion, market entry and exit.

\author{
Florian Baumann \\ University of Tübingen \\ Department of Economics (V1) \\ Melanchthonstrasse 30 \\ 72074 Tübingen \\ Germany \\ florian.baumann@uni-tuebingen.de
}

I'd like to thank Tim Friehe, Laszlo Goerke, and the participants of the 5th workshop of the Research Network of the German Research Foundation "Flexibility in Heterogeneous Labour Markets” for helpful comments. Financial Support by the German Research Foundation is gratefully acknowledged. 


\section{Introduction}

To gain a proper understanding of the effects of regulations and other interventions by public authorities, it is necessary to include possibilities to circumvent such rules into the analysis. To give an example in line with this, a voluminous literature has developed investigating the effects of tax evasion, starting with the seminal contribution by Allingham and Sandmo (1972). Labor markets, especially in continental Europe, are often characterized by substantial regulations. In this paper, our focus is on employment protection legislation. Employment protection restricts the employer's freedom to reduce the workforce of her firm or at least increases costs for such a downward adjustment. In most of the literature on employment protection, it is (implicitly) assumed that the corresponding regulations can be perfectly enforced. However, this may not always be warranted. As employment protection is normally associated with costs for the employer, an incentive exists to circumvent these regulations. Furthermore, as employment protection rules intervene with the employer's decisions in the event of downward adjustments in employment, they restrain the employer's freedom of choice when the firm faces unfavorable business conditions. Therefore, the employer may simply not be able to afford the expenses associated with these regulations. Thus, evasion should be taken into account when assessing the presumed effects of employment protection legislation.

In this paper, we capture limited enforceability of employment protection legislation by allowing firms to avoid payment of firing costs by leaving the market. Market exit costs can fall short of individual firing costs. First, it may be that firms cannot afford the required payments as they do not earn any profit. Second, in the case of market exit, incentives to default on firing costs may be enhanced, because penalties cannot be imposed (see, e.g., Belviso 2003). To incorporate the market exit decision meaningfully, we use a partial equilibrium model of imperfect competition on product markets, allowing for an endogenous number of competitors. We choose a model of monopolistic competition in the manner of Dixit and Stiglitz (1977), enriched by firing costs and demand shocks. ${ }^{1}$ As in Blanchard and Giavazzi (2003), we allow for market power of firms to depend on the number

\footnotetext{
${ }^{1}$ Other contributions investigating employment protection in models of monopolistic competition are Amable and Gatti (2006), Bertola (1994), and Burda (1991), all of which, however, assume perfect enforcement of firing costs.
} 
of firms in the market. We assume idiosyncratic shocks, such that firms are homogeneous ex-ante but heterogeneous ex-post as in Melitz (2003). Consequently, a threshold for market exit of single firms can be derived. The reason for market exit being a profitable strategy is that firing costs add a fixed-costs component to firms profits, which the firm can save on by leaving the market.

We find that, firing costs are neutral with respect to market entry in the case of perfect enforcement. This no longer holds if evasion of firing costs is allowed for and market power of firms depends on the number of firms active in the market. In this case, positive firing costs increase the number of firms entering the market. However, due to market exit, the number of firms active is always lower for positive firing costs than for zero firing costs if evasion of firing costs by market exit is possible. For our results on hirings, dismissals, and total employment we rely on a simulation. We find that the possibility to evade firing costs by market exit mitigates the effects of employment protection on hirings and dismissals. Concerning employment, we establish that the possibility to circumvent firing costs by market exit can reverse the sign of the change in employment when firing costs are increased. A final observation is that, as employment protection reduces efficiency in the present set-up by assumption, the possibility to evade firing costs actually attenuates the adverse efficiency effects of firing costs in the market equilibrium.

Our findings can be related to real-world observations. Blanchard and Portugal (2001), comparing the labor markets in the USA and Portugal, conclude that in Portugal, a country with stringent employment protection rules, a much higher share of labor market flows is accounted for by market entry and exit of firms than in the USA, a country characterized by limited job security regulations. Using these findings to evaluate the results in our paper, we conclude that taking account of only limited enforcement of employment protection rules in the case of market exit is important for a proper assessment of their real effects.

Literature. Although most contributions on employment protection assume perfect enforcement, some authors allow for noncompliance with existing rules. The paper nearest to our analysis is Samaniego (2006). Using a neoclassical general equilibrium model, Samaniego investigates the consequences of limited enforcement of employment protection rules, which, as in the model presented here, is due to non-enforcement of firing costs in the event of market exit. Market exit is driven by firm-specific shocks in fixed costs. Samaniego calibrates his 
model on the basis of data for the USA. Without the evasion of firing costs by market exit, firing costs reduce labor reallocation due to less variability in employment per firm as well as lower market entry and exit rates. In contrast, with the evasion of firing costs, job creation and job destruction due to market entry and exit is higher for positive firing costs and firms are less reluctant in hiring workers. The results presented in this paper are in line with the results found by Samaniego, except that in our analysis the effect on market entry is less pronounced. At the expense of a less detailed model environment, the set-up used in this paper allows for some additional insights with respect to the market entry decision and the efficiency effects of firing costs.

Other contributions which allow for limited enforcement of employment protection rules due to limited assets of firms are Belviso (2003) and Blanchard and Tirole (2004). Belviso (2003) investigates a search- and matching model with severance payments and firing costs, but allows firms to declare bankruptcy in the occurrence of a negative shock, where bankruptcy frees firms from their obligations. As a consequence of the assumption of each firm employing only one worker, firms always declare bankruptcy if realizing low productivity, and firing costs only affect wage bargaining, whereas they have no direct effect on the decision to dismiss an employee. Blanchard and Tirole (2004) discuss optimal firing taxes for financing unemployment benefits and consider "shallow pockets" of firms as an additional constraint for the optimization problem of the benevolent planner. This necessitates a decrease in optimal firing taxes because otherwise, as results in the model presented here, firms are driven out of the market. ${ }^{2}$

There can be other reasons for limited enforceability of employment protection regulations not related to limited assets or market exit. See, for instance, Martin et al. (2004) or Galdon-Sanchez and Güell (2003) on asymmetric information and Blanchard and Landier (2002) or Neugart and Storrie (2006) on fixed-term employment contracts or the use of temporary work agency employment.

The rest of the paper is organized as follows. In Section 2, the model is described. Section

\footnotetext{
${ }^{2}$ The possibility of limited assets of firms hampering enforcement of employment protection is also mentioned by Boeri (1999). Outside the realm of labor economics, the topic of limited assets impeding the enforcement of legal rules has been in particular discussed in the context of tort law. An early contribution in this line is Shavell (1986).
} 
3 investigates the effects firing costs exert on the equilibrium. As the model does not allow for a closed-form solution, we present a simulation in Section 4 to provide further insights. Section 5 concludes this study.

\section{The model}

\subsection{Description}

We investigate a model with a continuum of goods produced and consumed. In this section, we first derive the demand functions for the goods produced. Subsequently, we describe the production sector. The equilibrium is derived in Section 2.2.

Demand. In the economy, the representative consumer's preferences are given by a CES-utility function over a continuum of differentiated consumption goods, indexed by $j$, $j \in[0, \bar{n}]$,

$$
U=\left[\int_{0}^{\bar{n}} a_{j}\left(x_{j}\right)^{1-\alpha} d j\right]^{\frac{1}{1-\alpha}}
$$

where $x_{j}$ is the amount of good $j$ consumed and $\alpha \in(0,1)$ equals the inverse of the elasticity of substitution between goods. As in Blanchard and Giavazzi (2003) the value of $\alpha$ may depend on the number of competitors active in the market, $n$, with $\alpha^{\prime}(n) \leq 0 .^{3}$ The elasticity of substitution may increase in the number of varieties produced as a higher number of varieties abates the differentiation between products, and therefore eases substitution between goods for consumers. The higher the elasticity of substitution between goods, the lower the market power of each single firm is. The number of varieties of the consumption good for which a blueprint exists is depicted by $\bar{n}$ and determined by market entry decisions of firms in the production sector, where each firm is able to produce one variety of the consumption good. As market exit is allowed for, the number of firms active in the market can differ from the number of blueprints available, $n \leq \bar{n}$. Furthermore, $a_{j}$ is a stochastic preference parameter which is distributed in the interval $[0, \bar{a}], \bar{a}>0$, according to the twice differentiable cumulative distribution function $G\left(a_{j}\right)$, which is the same for every commodity $j$. The corresponding density function is labeled $g\left(a_{j}\right)$. The realizations of the preference

\footnotetext{
${ }^{3}$ See also, e.g., Ebell and Haefke (2003).
} 
parameters are mutually independent. With $Y$ as total spending on consumption goods, taken as exogenous, residual demand (the inverse demand function) for a variety $i, i \in[0, \bar{n}]$, is given by

$$
p_{i}=\frac{a_{i} Y}{\Omega} x_{i}^{-\alpha}
$$

where $p_{i}$ is the price of commodity $i$ and

$$
\begin{aligned}
\Omega & =\left[\int_{0}^{\bar{n}} a_{j}\left(x_{j}\right)^{1-\alpha} d j\right] \\
& =\bar{n}\left[\int_{0}^{\bar{a}} a(x(a))^{1-\alpha} d G(a)\right]
\end{aligned}
$$

is a measure for effective output of consumption goods. The last equality sign in equation (3) follows from the common distribution of the preference parameter for all commodities $j$. Residual demand for firm $i$ is higher, the lower the value of effective output $\Omega$ and the higher the own preference parameter $a_{i}$ or total spending $Y$ are.

Production sector. The production sector is characterized by monopolistic competition on goods markets. A continuum of firms exists, with the mass (number) of firms, $\bar{n}$, being determined by free market entry. Each firm is endowed with a blueprint to produce one variety of the consumption good and uses the same production technology with labor as the only input. Each worker employed produces one unit of the commodity. We restrict attention to a two-period setting. ${ }^{4}$ The time structure is described in Figure 1.

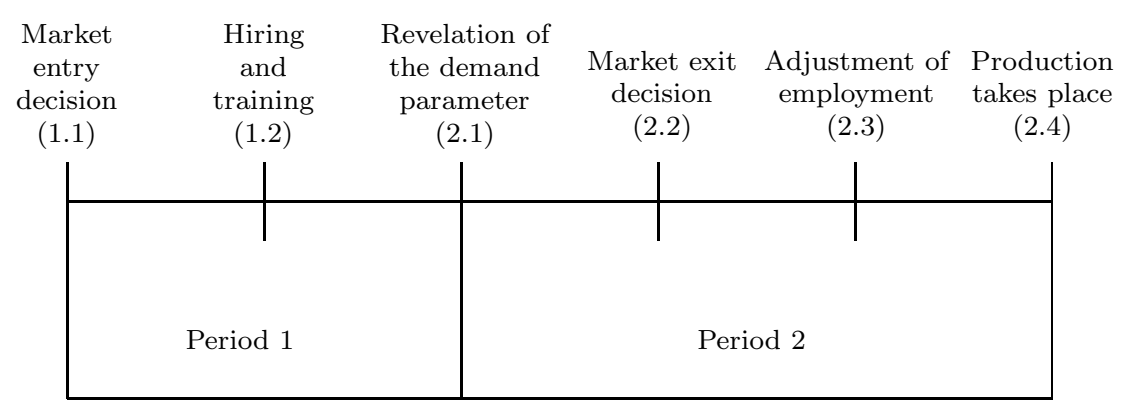

Figure 1: Time structure of the model

\footnotetext{
${ }^{4}$ We neglect discounting between periods for notational convenience.
} 
As in Melitz (2003), we investigate a setting in which firms are homogenous ex-ante (period 1) but heterogenous ex-post (period 2). The realization of the demand parameter is not revealed before the beginning of the second period (stage (2.1)). At the beginning of period 1, firms decide whether to enter the market, stage (1.1), which involves the development of a new blueprint for a variety of the consumption good. Entry is associated with fixed market entry costs $C$, which are sunk. For production to take place in period 2, firms have to hire and train workers in period 1 (stage (1.2)), determining the number of initially employed workers per firm $\bar{x}_{i}$. The consideration underlying this assumption is that workers need firmspecific knowledge for production, and training to be time-consuming. Training costs are given as $h$ per worker. The decisions with respect to market entry and hiring are therefore made knowing only the distribution of the preference parameter $a$. After the realization of the demand parameters for the commodities at the beginning of period 2, each firm can decide whether to stay or to exit the market, stage (2.2). Firms that stay in the market may adjust their employment level at stage (2.3). However, as a consequence of time-consuming training, only a downward adjustment of initial employment is possible. Costs per worker employed in period 2 are given by the wage $w$, taken as exogenous, whereas the firm has to pay firing costs $T<w$ for each worker laid off..$^{5}$ To illustrate the effects of limited enforcement of employment protection rules, we distinguish two scenarios with respect to the market exit decision. In scenario A, which serves the purpose of a benchmark scenario, market exit does not allow for a saving on firing costs. Market exit corresponds to employment of zero in period 2 and accordingly market exit costs are given by $T \bar{x}_{i}$. In this case, market exit is never a profitable strategy. In scenario B, in the event of market exit, employment protection rules cannot be enforced and market exit costs equal zero. Consequently, all firms that would otherwise incur losses close down.

\subsection{Equilibrium}

The model is solved by backward induction. We start with the decision on employment in period 2 of a firm staying in the market (stage (2.3)), determine market exit decisions (stage (2.2)), describe the optimal hiring policy (stage (1.2)) and finally point out the number of

\footnotetext{
${ }^{5}$ We assume firing costs $T$ to fall short of the wage $w$ as otherwise dismissals other than associated with market exit would never take place. Nevertheless higher firing costs could be allowed for, although this would not yield any new insights.
} 
firms entering the market (stage (1.1)). As firms can be readily described by the realization of the respective demand parameter $a_{i}$ in period 2 and are symmetric in period 1 , in what follows we leave out the subscript for firms.

Adjustment of employment. Firms that stay in the market in period 2 decide whether to keep employment at the level of initial hirings $\bar{x}$ or to lay off some of their employees. In choosing employment, firms maximize profits in period $2, \pi(a)$, subject to the constraint $x(a) \leq \bar{x}$. Profits in period 2 are given by

$$
\begin{aligned}
\pi(a) & =p(a) x(a)-w x(a)-T[\bar{x}-x(a)] \\
& =\frac{a Y}{\Omega} x(a)^{1-\alpha}-(w-T) x(a)-T \bar{x} .
\end{aligned}
$$

Firing costs change the cost structure of firms because effective marginal costs of output/employment, $(w-T)$, decline in firing costs whereas a fixed cost component, $T \bar{x}$, is added. From maximization of profits in period 2, one finds a threshold value for the preference parameter $a, a^{k}$, such that optimal employment is restricted by initial hirings $\bar{x}$ for $a>a^{k}$, whereas a firm that stays in the market lays off part of its workforce for lower values of the preference parameter, where

$$
a^{k}=\frac{w-T}{1-\alpha} \frac{\Omega}{Y} \bar{x}^{\alpha}
$$

The optimal employment-price combination for an active firm is given by

$$
\left(x^{*}(a) ; p^{*}(a)\right)=\left\{\begin{array}{lll}
\left(\frac{1-\alpha}{w-T} \frac{a Y}{\Omega}\right)^{\frac{1}{\alpha}} ; & \frac{w-T}{1-\alpha} ; & a \leq a^{k} \\
\bar{x} ; & \frac{a Y}{\Omega} \bar{x}^{-\alpha} ; & a>a^{k} .
\end{array}\right.
$$

Market exit. A firm leaves the market if maximized profits in period 2 fall short of market exit costs. As marginal profits become infinite for employment approaching zero and therefore would exceed the wage payment $w$, market exit (that is zero employment) can only be profitable if it allows for a saving on the fixed costs component in period 2. Accordingly, in scenario A, market exit is never a profitable strategy as it does not allow for a saving on firing costs, $a_{A}^{b}=0$. In contrast, in scenario B, one finds a second threshold for the demand parameter, $a_{B}^{b} \geq 0$, such that $\pi\left(a_{B}^{b}\right)=0$ and firms which realize a preference parameter 
$a<a_{B}^{b}$ exit the market. Inserting equation (6) into equation (4), $a_{B}^{b}$ is described by

$$
a_{B}^{b}= \begin{cases}\left(\frac{w-T}{1-\alpha}\right)^{1-\alpha}\left(\frac{T}{\alpha}\right)^{\alpha} \frac{\Omega}{Y} \bar{x}^{\alpha} ; & T \leq \alpha w \\ w \frac{\Omega}{Y} \bar{x}^{\alpha} ; & T>\alpha w .\end{cases}
$$

The threshold value for market exit increases in effective output $\Omega$ as residual demand for each single firm decreases. Furthermore, $a_{B}^{b}$ increases in initial employment $\bar{x}$ because of the higher fixed costs. Finally, with respect to firing costs, the threshold value $a_{B}^{b}$ equals zero for zero firing costs $(T=0)$ but is positive for positive values of firing costs. Ceteris paribus, the threshold value increases with firing costs for $T<\alpha w$ to reach a maximum at $T=\alpha w$. The critical value for firing costs, $\alpha w$, is due to the fact that individual dismissals cannot be profitable for higher values of firing costs, as the optimal price in the case of a downward adjustment in employment, $\frac{w-T}{1-\alpha}$, would fall short of production costs per unit output, given by the wage $w$. Accordingly, firms either exit the market or stay active while keeping employment at $\bar{x}$, but never lay off workers individually in the case of $T>\alpha w \cdot{ }^{6}$ As a consequence, a further increase in firing costs does not affect profits of the firm any longer, and the threshold value $a_{B}^{b}$ is solely determined by a comparison of the price the firm can charge keeping its employment at $\bar{x}$ and the wage costs per unit produced.

With $G\left(a_{l}^{b}\right)$ as the probability of exit for each firm, the number of firms in the market in period 2 equals $n=\bar{n}\left(1-G\left(a_{l}^{b}\right)\right)$, with $l=A, B$, denoting the scenario under consideration. Taking the option of market exit into account, profits in period 2 are described by

$$
\pi(a)= \begin{cases}0 ; & a \leq a_{l}^{b} \\ \alpha\left(\frac{1-\alpha}{w-T}\right)^{\frac{1-\alpha}{\alpha}}\left(\frac{a Y}{\Omega}\right)^{\frac{1}{\alpha}}-T \bar{x} ; & a_{l}^{b}<a \leq a^{k} \\ \frac{a Y}{\Omega} \bar{x}^{1-\alpha}-w \bar{x} ; & a>a^{k},\end{cases}
$$

$l=A, B$. In scenario $\mathrm{B}$, for $T>\alpha w, a^{k}<a_{B}^{b}$ and profits in period 2 are described by the first and the last line in equation (8) only, with $a^{k}$ being replaced by $a_{B}^{b}$.

Initial employment. In period 1, each firm must decide about the number of workers to hire, $\bar{x}$. Firms choose initial employment in order to maximize the ex-ante expected profits

\footnotetext{
${ }^{6}$ Note that for $T=\alpha w$, the two threshold values for the preference parameter coincide, $a^{k}=a_{B}^{b}$.
} 
net of training costs,

$$
\Pi=\int_{0}^{\bar{a}} \pi(a) d G(a)-h \bar{x} .
$$

From equations (8) and (9), optimal initial employment is determined by

$$
\frac{1-\alpha}{\bar{x}^{\alpha}} \frac{Y}{\Omega} \int_{a^{k}}^{\bar{a}} a d G(a)-w\left[1-G\left(a^{k}\right)\right]-T\left[G\left(a^{k}\right)-G\left(a_{l}^{b}\right)\right]-h=0,
$$

$l=A, B$, for scenario $\mathrm{A}$ and for scenario $\mathrm{B}$ if $T<\alpha w$. For $T>\alpha w$ in scenario B, $a^{k}$ has to be replaced by $a_{B}^{b}$ and the actual level of firing costs does not affect the number of workers to hire. Equation (10) states that, in equilibrium, the first term, namely expected marginal revenue of the last worker hired, equals marginal costs. Beside training costs $h$, the latter comprise either the wage $w$ in case the (last) worker remains employed after the realization of the preference parameter $\left(a \geq a^{k}\right)$ or firing costs $T$ in the event of an individual dismissal $\left(a_{l}^{b}<a<a^{k}\right)$. In the event of market exit in scenario B, firing costs are reduced to zero. In what follows, we assume the second-order condition for a profit maximum to be fulfilled, that is for scenario $\mathrm{B}$ and $T<\alpha w$

$$
-\frac{\alpha(1-\alpha)}{\bar{x}^{1+\alpha}} \frac{Y}{\Omega} \int_{a^{k}}^{\bar{a}} a d G(a)+g\left(a_{B}^{b}\right) \alpha T \frac{a_{B}^{b}}{\bar{x}}<0
$$

is assumed to hold. ${ }^{7}$

Market entry. Firms enter the market as long as ex-ante expected profits, $\Pi$, exceed the market entry costs $C$. Integrating equation (8), subtracting training costs and taking into account the first-order condition for initial employment, equation (10), the market entry condition is given by ${ }^{8}$

$$
\Pi=\frac{\alpha Y}{\bar{n}}=C
$$

for both scenarios A and B. The number of firms entering the market is determined by overall demand $Y$, the elasticity of individual demand $\alpha$, also indicating market power of firms, and entry costs $C$. The number of firms entering the market increases with total spending and

\footnotetext{
${ }^{7}$ Marginal revenues decrease as initial employment increases, however, marginal costs decrease in scenario B for $T<\alpha w$ as well. Marginal costs decrease because higher initial employment increases the fixed costs component and thereby raises the probability of market exit, in which case firing costs are saved. Equation (11) states that the decrease in marginal revenue more than offsets the decrease in marginal costs when initial employment is increased.

${ }^{8}$ For calculations see Appendix A.
} 
market power per firm, and decreases with market entry costs.

Equilibrium. The equilibrium of the economy is defined by the system of equations (3), (5), (6), (7), (10), and (12) determining the endogenous variables

- $\bar{n}$, the number of firms entering the market,

- $a^{k}$ and $a_{l}^{b}, l=A, B$, identifying the two critical values of the preference parameter,

- $\bar{x}$, the number of initial hirings in period 1 per firm,

- the optimal employment rule in period $2, x^{*}(a)$, and

- the value of effective output $\Omega$.

The number of firms entering the market, $\bar{n}$, together with the threshold value for market exit, $a_{l}^{b}, l=A, B$, determine the number of firms active in period $2, n=\bar{n}\left(1-G\left(a_{l}^{b}\right)\right)$.

\section{The effects of firing costs}

Market entry and the number of competitors in the market. Analyzing the impact firing costs exert on the number of firms that initially enter the market, $\bar{n}$, one can distinguish four cases, specified by whether market exit allows for a saving on firing costs (scenario A versus scenario B) and whether the (absolute) elasticity of demand for each single firm, $1 / \alpha$, is constant or increases in the number of firms active in the market, $n$.

First, if the elasticity of demand for each firm is independent of the number of firms in the market, $\alpha^{\prime}(n)=0$, the number of firms entering the market, $\bar{n}$, is independent of the existence or the level of firing costs in both scenarios A and B. From the market entry condition, equation (12), this number is solely determined by the exogenous parameters for entry costs, $C$, total spending, $Y$ and the constant value of $\alpha$.

In contrast, if the elasticity of demand increases in the number of varieties actually produced in period $2, \alpha^{\prime}(n)<0$, the results differ according to the scenario considered. For scenario A, without the possibility to circumvent firing costs by market exit, no market exit takes place. The number of firms active in period 2 always coincides with the number of firms entering the market in period $1, n=\bar{n}$. Therefore, the market entry condition, 
equation (12), still determines the number of firms entering the market independently of the existence or the level of firing costs according to $\frac{\alpha(\bar{n})}{\bar{n}}=\frac{C}{Y} \cdot{ }^{9}$ Otherwise, with evasion of firing costs by market exit, scenario B, from equation (7) the threshold value for market exit, $a_{B}^{b}$ is positive for $T>0$ and zero for $T=0$. For positive firing costs the number of firms active in period 2 falls short of the number of firms entering in period $1, n=\bar{n}\left(1-G\left(a_{B}^{b}\right)\right)$, whereas $n=\bar{n}$ holds for $T=0$. Accordingly, the value of $\alpha$ would be higher for $T>0$ than for $T=0$ if the number of firms entering the market were the same. With $\bar{n}_{T=0}\left(\bar{n}_{T>0}\right)$ denoting the equilibrium number of firms entering in the case of zero (positive) firing costs, ex-ante expected profits would exceed market entry costs if $T>0$ and $\bar{n}_{T>0}=\bar{n}_{T=0}$ were to hold. This implies that additional firms enter the market, resulting in $\bar{n}_{T>0}>\bar{n}_{T=0}$.

These results can be explained as follows: For scenario A, in equilibrium, the increase in labor (adjustment) costs is just offset by a decrease in overall effective output and the accompanying increase in residual demand per firm, leaving ex-ante expected profits unchanged for a given number of firms entering the market. This also holds true for the case involving the evasion of firing costs by market exit, if the elasticity of substitution does not depend on the number of firms in the market. However, if the elasticity of demand increases with the number of varieties, an additional effect of firing costs comes into play. Market exit by some firms increases market power for the remaining firms. Profits of the remaining firms and therefore ex-ante expected profits increase. This leads to more firms entering the market until the market entry condition is reestablished.

Next, let us turn to the number of firms active in period 2, $n$. For scenario A, as no market exit takes place, this number always coincides with the number of firms entering the market. In contrast, in scenario $\mathrm{B}$, for a positive level of firing costs some firms leave the market after the revelation of the preference parameters, such that $n_{T>0}<\bar{n}_{T>0}$. Furthermore, the number of firms active in period 2 is always lower for a positive level of firing costs than for the case of no firing costs in scenario B. Whereas this is obvious for $\alpha^{\prime}(n)=0$ as $\bar{n}_{T>0}=\bar{n}_{T=0}$ in this case, this also holds for $\alpha^{\prime}(n)<0$. To see this, assume $n_{T>0} \geq n_{T=0}=\bar{n}_{T=0}$. This would imply $\alpha_{T>0} \leq \alpha_{T=0}$, and the number of firms entering the market would have to be

\footnotetext{
${ }^{9}$ Note that

$$
\frac{d\left(\frac{\alpha(\bar{n})}{\bar{n}}\right)}{d \bar{n}}=\frac{\alpha^{\prime}(\bar{n}) \bar{n}-\alpha(\bar{n})}{\bar{n}^{2}}<0
$$

and therefore the number of firms entering the market $\bar{n}$ is unique.
} 
equal to or fall short of $\bar{n}_{T=0}$ to assure equality in equation (12), contrary to what has been established above.

The findings for market entry and the number of firms active in period 2 are described in Table 1 and summarized in Result 1.

\begin{tabular}{|c|c|c|}
\hline & $\alpha^{\prime}(n)=0$ & $\alpha^{\prime}(n)<0$ \\
\hline Scenario A & $n_{T \geq 0}=\bar{n}_{T \geq 0}=\bar{n}_{T=0}$ & $n_{T \geq 0}=\bar{n}_{T \geq 0}=\bar{n}_{T=0}$ \\
\hline Scenario B & $n_{T>0}<n_{T=0}=\bar{n}_{T \geq 0}=\bar{n}_{T=0}$ & $n_{T>0}<n_{T=0}=\bar{n}_{T=0}<\bar{n}_{T>0}$ \\
\hline
\end{tabular}

Table 1: Market entry and number of firms active in period 2

Result 1: Assuming market power of firms to decrease with the number of firms active in the market in period 2, $\alpha^{\prime}(n)<0$, and allowing for evasion of firing costs by market exit (scenario B), more firms enter the market for positive firing costs than in the absence of firing costs. In contrast, if evasion of firing costs is not possible (scenario A) or market power of firms is independent of the number of competitors, $\alpha^{\prime}(n)=0$, the number of firms entering the market is independent of the existence or the level of firing costs. Finally, in scenario $B$, for positive firing costs the number of firms active in period 2 is always lower than for zero firing costs.

In the following, for reasons of tractability, we restrict the analysis to the case $\alpha^{\prime}(n)=0$, that is market power of firms is exogenous and as a result the number of firms entering the market is always independent of the level of firing costs.

Effective output and utility of the representative consumer. Firing costs represent additional labor costs for firms. To reestablish the market entry condition after an increase in firing costs, these higher costs must be compensated by higher profits resulting from a shift in residual demand faced by each single firm. This must be achieved by a decrease in effective output $\Omega$, see equation (2). Indeed, with ex-ante profits, $\Pi$, equal to market entry costs, $C$, the change in effective output when firing costs are increased is given by

$$
\frac{d \Omega}{d T}=-\frac{\frac{\partial \Pi}{\partial T}}{\frac{\partial \Pi}{\partial \Omega}}=-\frac{\bar{n} \Omega}{Y} \int_{a_{l}^{b}}^{a^{k}}\left[\bar{x}-x^{*}(a)\right] d G(a) \leq 0
$$


$l=A, B$. The integral term is the number of expected dismissals and corresponds to the direct effect firing costs have on ex-ante expected profits, $\frac{\partial \Pi}{\partial T} \cdot{ }^{10}$ Effective output decreases with firing costs and only in scenario B for $T \geq \alpha w, \Omega$ will no longer be affected by a further increase in firing costs as no individual dismissals take place. Moreover, as can be deduced from equation (1) in conjunction with equation (3), the representative consumer's utility unambiguously depends positively on effective output for a given elasticity of substitution $\alpha^{-1}$.

Result 2: Effective output generally decreases in firing costs. Only if evasion of firing costs by market exit is possible and no individual dismissals take place ( $T \geq \alpha w$ ), a further increase in firing costs leaves effective output unaffected. The decline in effective output translates into a reduced utility level for the representative consumer in equilibrium.

Market exit and initial employment. Before turning to the simulation in the next section, we report the results of the comparative static analysis with respect to initial employment, $\bar{x}$, and the threshold value for market exit, $a_{B}^{b}$ in scenario B. ${ }^{11}$ For the change in the probability of market exit in scenario $\mathrm{B}$ (for $T<\alpha w$ ) one obtains

$$
\begin{aligned}
\frac{d G\left(a_{B}^{b}\right)}{d T} & =g\left(a_{B}^{b}\right) a_{B}^{b}\left[\frac{\alpha w-T}{(w-T) T}+\frac{\alpha}{\bar{x}} \frac{d \bar{x}}{d T}+\frac{1}{\Omega} \frac{d \Omega}{d T}\right] \\
& =g\left(a_{B}^{b}\right) a_{B}^{b} \frac{G\left(a^{k}\right)-G\left(a_{B}^{b}\right)-\frac{1-\alpha}{\bar{x}^{\alpha}} \frac{Y}{\Omega} \int_{a^{k}}^{\bar{a}} a d G(a) \frac{\alpha w-T}{(w-T) T}}{\bar{x}^{\alpha} \Delta}
\end{aligned}
$$

with

$$
\Delta=-\frac{1-\alpha}{\bar{x}^{2 \alpha}} \frac{Y}{\Omega} \int_{a^{k}}^{\bar{a}} a d G(a)+T g\left(a_{B}^{b}\right) \frac{a_{B}^{b}}{\bar{x}^{\alpha}}<0 .
$$

$\Delta<0$ holds according to the assumption of the second-order condition for a maximum of profits being fulfilled, see equation (11). The direct effect of firing costs is to increase the threshold value $a_{B}^{b}$. However, this effect may be counteracted by the reduction in effective output $\Omega$ or a decrease in initial employment $\bar{x}$. The reduction in effective output implies an increase in residual demand and profits of firms, whereas a decrease in initial employment would lower the fixed costs component of profits in period 2. In scenario A $\left(a_{A}^{b}=0\right)$ or

\footnotetext{
${ }^{10}$ This follows from an application of Hotelling's Lemma.

${ }^{11}$ The calculations can be retraced in Appendix B.
} 
for firing costs exceeding $\alpha w$ in scenario $\mathrm{B}$ an increase in firing costs has no effect on the probability of market exit.

For the change in the number of workers hired in period 1 one finds

$$
\frac{d \bar{x}}{d T}=\bar{x}^{1-\alpha}\left[\frac{G\left(a^{k}\right)-G\left(a_{l}^{b}\right)}{\alpha \Delta}-\frac{a_{l}^{b} g\left(a_{l}^{b}\right) \frac{\alpha w-T}{w-T}}{\alpha \Delta}\right]-\frac{\bar{x}}{\alpha \Omega} \frac{d \Omega}{d T},
$$

$l=A, B$. The direct effect of firing costs is to increase marginal costs of labor according to the probability of an individual dismissal $\left(G\left(a^{k}\right)-G\left(a_{l}^{b}\right)\right)$, reducing the optimal number of workers to hire. However, an increase in the probability of market exit would diminish marginal costs and the decrease in effective output increases marginal revenue, which both raise initial employment. These two effects are indicated by the second and third term in equation (16). From equation (16), whether initial employment increases or decreases with firing costs in scenario B cannot be predicted. In contrast, in scenario A, initial employment always decreases in firing costs. In this case, from equations (3) and (6), as optimal employment in period 2 increases with firing costs for all $a<a^{k}$, the decrease in effective output $\Omega$ can only be achieved by a decrease in employment for $a>a^{k}$, that is lower initial employment $\bar{x} .^{12}$

\section{Simulation}

The purpose of the simulation is, first, to exemplify the change in initial employment and the probability of market exit, for which no unambiguous results are found in the comparative static analysis. Furthermore, this section investigates the number of dismissals and overall employment in period 2 as well as effective output to allow for a comparison between the scenarios with perfect and limited enforcement of employment protection regulations.

Parameter values and functions used for the simulation. The parameter values and functions used are summarized in Table 2.

For the preference parameter $a$, we assume a uniform distribution in the interval $[0,10]$ as indicated by $G(a)$ in Table 2 . The wage $w$ serves as a numeraire. Hiring costs amount to 20 per cent of wages. The parameter values for market entry costs $C$ and overall spending

\footnotetext{
${ }^{12}$ Note that $a_{A}^{b}=0$. Accordingly, the decrease in $\Omega$ can not be achieved by an increase in the probability of market exit.
} 


\begin{tabular}{|c|c|}
\hline Parameter/Function & Value(s) \\
\hline \hline$w$ & 1 \\
$h$ & 0.2 \\
$C$ & 2 \\
$Y$ & 200 \\
$G(a)$ & $\frac{a}{10}$ \\
$\bar{a}$ & 10 \\
$\alpha$ & 0.5 \\
\hline
\end{tabular}

Table 2: Parameter values and functions used in the simulation

$Y$ only affect the absolute values of the outcomes.

Probability of market exit/Number of firms. As stated in Result 1, for $\alpha$ being independent of the number of active firms, the number of firms that initially enter the market $\bar{n}$ does not depend on firing costs. In contrast, the number of firms active in period 2 depends on the probability of market exit, $G\left(a_{l}^{b}\right)$, and therefore on the threshold value for the demand parameter $a_{l}^{b}, l=A, B$. In the comparative static analysis no clear cut results could be derived for the change of $a_{l}^{b}$ with respect to firing costs for scenario B. In Figure 2 we report the number of firms active, $n$, as a share of $\bar{n}$. The number of firms entering the market equals $\bar{n}=50$. The horizontal axis gives firing costs as a percentage share of wages. The dashed line depicts the share of firms still active in period 2 if no evasion of firing costs is possible, scenario $\mathrm{A}$, in which case no market exit takes place $(n / \bar{n}=1)$. In contrast, for scenario B, the share of firms active in period $2,1-\left(G_{B}^{b}\right)$, is represented by the solid line. In scenario B, an increase in firing costs always raises the probability of market exit in the simulations until the critical value of $T=\alpha w=0.5$ is reached, that is the direct effect of firing costs to increase the threshold for market exit always dominates in the simulation. The number of firms active for $T=0.5$ equals $n=36.689$ implying a probability of market exit of 24.62 per cent. For firing costs higher than the critical value, a further increase has no additional effect on the probability of market exit.

Initial employment. Figure 3 depicts the number of workers hired in period $1, \bar{x}$, as a share of initial hirings in the absence of firing costs, $\bar{x}_{T=0}$, for the two scenarios $\mathrm{A}$ and B. Again the horizontal axis corresponds to the ratio of firing costs to wages. Without firing costs, initial employment per firm amounts to $\bar{x}_{T=0}=2.375$. The dashed (solid) line gives 


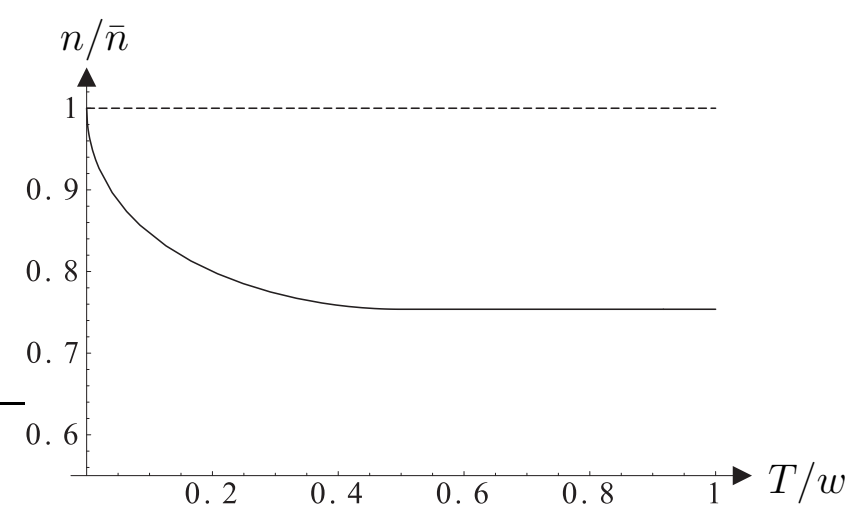

Figure 2: Active firms in period 2

initial hirings for scenario A (B). For $T<0.5$ in the simulations, initial hirings also decrease in firing costs in scenario B. This means that the direct increase in labor (adjustment) costs dominates the two indirect effects of a reduction in labor costs due to a higher probability of market exit in scenario B and the increase in marginal revenue due to lower effective output of competing firms. However, the effect of an increase in firing costs on initial hirings is mitigated when possibilities of evasion are taken into account.

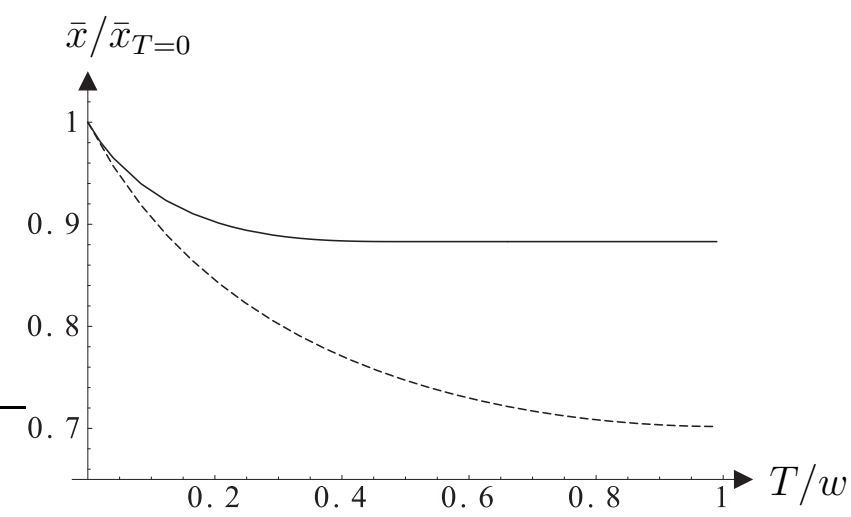

Figure 3: Employment in period 1

Dismissals. The number of dismissals in period 2 is given by

$$
\begin{aligned}
D & =\bar{n} \int_{0}^{\bar{a}}\left(\bar{x}-x^{*}(a)\right) d G(a) \\
& =\bar{x} \bar{n} G\left(a_{l}^{b}\right)+\bar{n} \int_{a_{l}^{b}}^{\bar{a}}\left(\bar{x}-x^{*}(a)\right) d G(a)
\end{aligned}
$$


$l=A, B$. As illustrated in the second line of equation (17), the number of dismissals can be broken down into dismissals due to market exit, the first term, and individual dismissals by firms that stay in the market in period 2, the second term. There are three different ways in which firing costs alter the number of dismissals. First, for firms active in period 2, labor demand increases for low levels of the demand parameter $a$ due to the decrease in effective marginal costs. Additionally, optimal employment in this case is also affected by the change in effective output $\Omega$. The decrease in effective output, $\Omega$, further increases optimal employment due to the increase in residual demand. Second, as shown above, initial hirings decrease in firing costs in the simulation for every scenario. These two effects translate into fewer dismissals taking place. However, there is a countervailing third effect if market exit allows for evasion of firing costs. The increase in the probability of market exit, associated with employment of zero in period 2, ceteris paribus raises the number of dismissals taking place in scenario B. In the simulations presented in this section, the first two effects dominate the third effect in scenario $\mathrm{B}$, that is the number of dismissals is found to decrease with firing costs, see Figure 4. The dashed (solid) line gives the number of dismissals relative to the number of dismissals for $T=0$, denoted $D_{T=0}$, for scenario A (B). As can be seen, the possibility to evade firing costs also dampens the effect firing costs exert on the number of dismissals. For $T>0.5$ in scenario B, all dismissals are due to market exit.

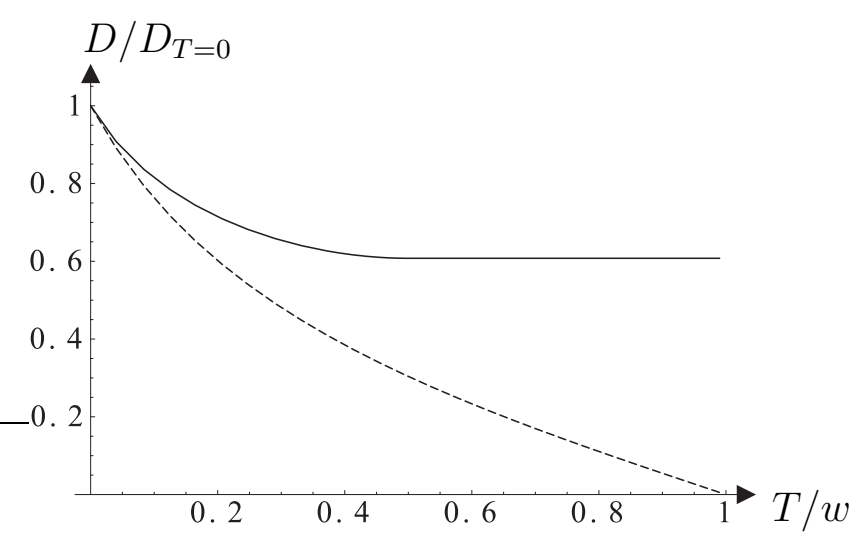

Figure 4: Dismissals

Employment in period 2. The number of workers hired in period 1 together with the 
decision on dismissals determine employment in period 2 , denoted $X$, where

$$
X=\bar{n} \bar{x}-D=\bar{n} \int_{0}^{\bar{a}} x^{*}(a) d G(a) .
$$

As both the number of workers hired as well as the number of workers dismissed generally decrease with firing costs in the simulations, the sign of the change in employment is at first ambiguous. Figure 5 contains the outcomes for employment in period 2 as a share of employment for $T=0, X_{T=0}$. The lines are drawn with the same conventions applied in the other figures with the solid (dashed) line representing the outcome in scenario B (A). Most strikingly, the figure conveys that the possibility to evade firing costs by market exit can actually alter the sign of the change in employment when firing costs are increased. For scenario A, starting from low firing costs, an increase in firing costs reduces employment. However, starting from high levels of firing costs, the outcome is reversed and actual employment eventually exceeds employment for zero firing costs.In contrast for scenario B, employment decreases in firing costs only for very low levels of firing costs but afterwards increases in firing costs until reaching a maximum for $T=\alpha w$. In the simulations, employment is higher in scenario A than in scenario B only for high values of firing costs. Note however, that a higher employment level is not directly associated with a more efficient allocation as the representative consumer's utility depends on effective output.

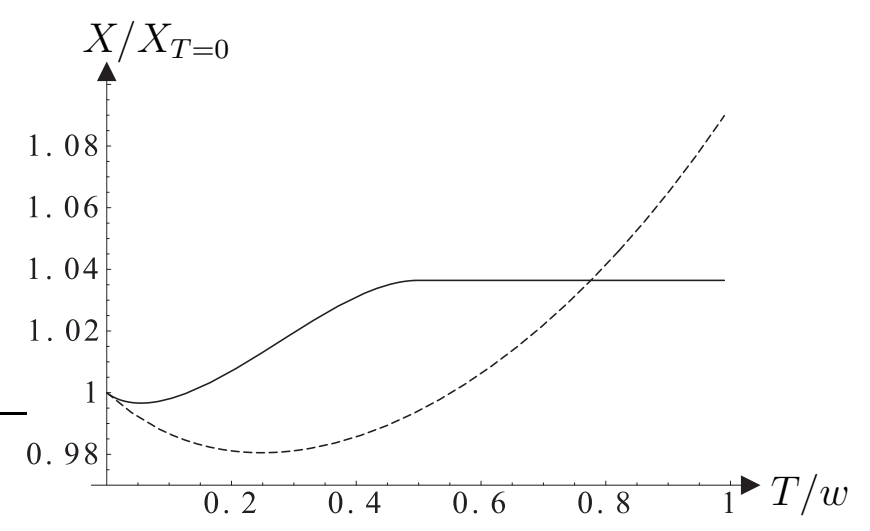

Figure 5: Employment in period 2

Effective output. As has been already established in Result 2, an increase in firing costs is associated with a decrease in effective output as long as individual dismissals take place. In contrast to employment in period 2, for the calculation of effective output, employ- 
ment is weighted by the respective realizations of the demand parameter and manipulated according to the elasticity of substitution between goods (see equation (3)). As illustrated in Figure 6, we find in the simulations that the possibility to evade firing costs mitigates the negative effect of firing costs on effective output. Again, the solid line depicts scenario B, whereas the dashed line represents the outcome in scenario A without market exit.

As the utility level achieved by the representative consumer is positively related to effective output (see Result 2), the possibility to circumvent employment protection is associated with a gain in efficiency in the model. However, one should note that in the setting used, there is no justification for the existence of employment protection rules. Nevertheless, the outcomes depicted in Figure 6 point to the interesting fact that the reduction in efficient output cannot be primarily addressed to market exit taking place. Effective output is even higher in scenario B with market exit than in scenario A where no market exit takes place.

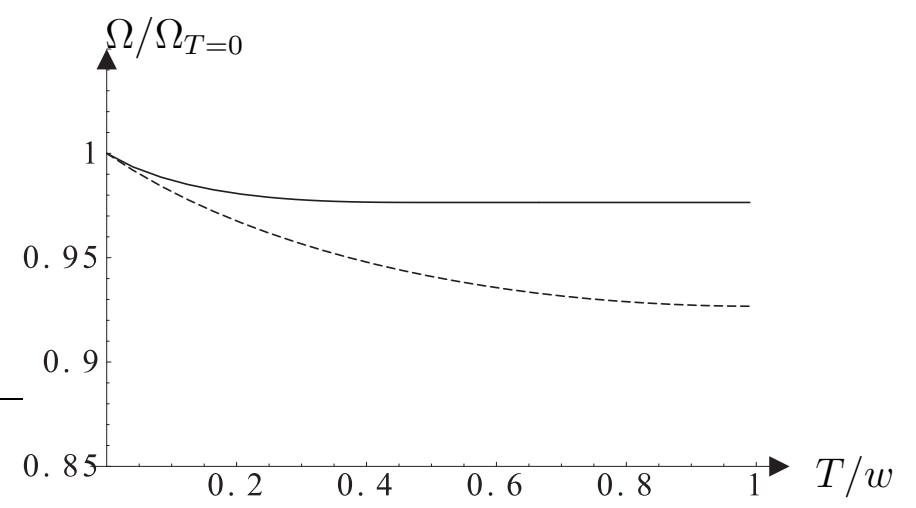

Figure 6: Effective output

\section{Conclusion}

The impact of labor market regulations depends on their enforcement. In this paper, we capture limited enforceability of employment protection legislation by allowing firms to circumvent regulations by market exit. Market exit may allow for evasion of firing costs either because firms are simply not able to pay the additional costs or because they have an incentive to default on their obligations in the event of market exit. If market power of firms depends on the number of firms active in the market, the number of firms initially entering 
the market is higher for positive firing costs than in the absence of firing costs. However, accounting for market exit, the reverse holds true for the number of firms actually taking up production. In the setup used and for given market power of firms, firing costs always reduce efficiency of the market equilibrium measured in terms of the representative consumer's utility. Using a simulation approach, we show that the negative effects of firing costs on efficiency can be mitigated if evasion of firing costs by market exit is allowed for. Furthermore, the possibility to circumvent firing costs can reverse the sign of the change in employment when firing costs are increased. 


\section{Appendix}

\section{A Derivation of equation (12)}

Assume that $T \leq \alpha w$ or that evasion of firing costs is not possible. Ex-ante expected profits less hiring costs are given by equation (9). Using equation (8) in conjunction with (6), noting that for $a<a_{l}^{b}, l=A, B$, firms leave the market, equation (9) can be transformed to

$$
\begin{aligned}
\Pi & =\frac{\alpha Y}{\Omega} \int_{a_{l}^{b}}^{a^{k}} a x^{*}(a)^{1-\alpha} d G(a)-T \bar{x}\left[G\left(a^{k}\right)-G\left(a_{l}^{b}\right)\right] \\
& +\frac{Y}{\Omega} \int_{a^{k}}^{\bar{a}} a \bar{x}^{1-\alpha} d G(a)-w\left[1-G\left(a^{k}\right)\right]-h \bar{x} .
\end{aligned}
$$

Multiplying the first-order condition for initial employment, equation (10), with $\bar{x}$ and substituting for $h \bar{x}$ in equation (19) one gets

$$
\begin{aligned}
\Pi & =\frac{\alpha Y}{\Omega} \int_{a_{l}^{b}}^{a^{k}} a x^{*}(a)^{1-\alpha} d G(a)+\frac{\alpha Y}{\Omega} \int_{a^{k}}^{\bar{a}} a \bar{x}^{1-\alpha} d G(a) \\
& =\frac{\alpha Y}{\Omega} \int_{a_{l}^{b}}^{\bar{a}} a x^{*}(a)^{1-\alpha} d G(a) .
\end{aligned}
$$

Recognizing the definition of $\Omega$ in equation (3), equation (20) can be directly transformed to equation (12) in the main text. For $T>\alpha w$ in scenario $\mathrm{B}$, the market entry condition can be derived in a similar manner.

\section{B Comparative static analysis - Derivation of equa- tions (14) and (16)}

From equations (5), (7), (10) and assuming $\alpha^{\prime}=0$, we formulate the following system for the respective changes in the values of $a^{k}, a_{l}^{b}(l=A, B)$, and $\bar{x}^{\alpha}$ for $T<\alpha w$ : 


$$
\begin{aligned}
& \underbrace{\left[\begin{array}{ccc}
1 & 0 & -\frac{w-T}{1-\alpha} \frac{\Omega}{Y} \\
0 & 1 & -\frac{a_{l}^{b}}{\bar{x}^{\alpha}} \\
0 & T g\left(a_{l}^{b}\right) & -\frac{1-\alpha}{\bar{x}^{2 \alpha}} \frac{Y}{\Omega} \int_{a^{k}}^{\bar{a}} a d G(a)
\end{array}\right]}_{Z}\left[\begin{array}{c}
d a^{k} \\
d a_{l}^{b} \\
d \bar{x}^{\alpha}
\end{array}\right] \\
& =\left[\begin{array}{cc}
-\frac{\bar{x}^{\alpha}}{1-\alpha} \frac{\Omega}{Y} & \frac{w-T}{1-\alpha} \frac{\bar{x}^{\alpha}}{Y} \\
a_{l}^{b} \frac{\alpha w-T}{(w-T) T} & \frac{a_{l}^{b}}{\Omega} \\
G\left(a^{k}\right)-G\left(a_{l}^{b}\right) & \frac{1-\alpha}{\bar{x}^{\alpha}} \frac{Y}{\Omega^{2}} \int_{a^{k}}^{\bar{a}} \operatorname{adg}(a)
\end{array}\right]\left[\begin{array}{c}
d T \\
d \Omega
\end{array}\right] .
\end{aligned}
$$

With $\operatorname{det}(Z)=\Delta($ see equation (15)), applying Cramer's rule yields

$$
d a_{l}^{b}=a_{l}^{b} \frac{G\left(a^{k}\right)-G\left(a_{l}^{b}\right)-\frac{1-\alpha}{\bar{x}^{\alpha}} \frac{Y}{\Omega} \int_{a^{k}}^{\bar{a}} a d G(a) \frac{\alpha w-T}{(w-T) T}}{\bar{x}^{\alpha} \Delta} d T+\frac{0}{\Delta} d \Omega
$$

and

$$
d \bar{x}^{\alpha}=\frac{G\left(a^{k}\right)-G\left(a_{l}^{b}\right)-a_{l}^{b} g\left(a_{l}^{b}\right) \frac{\alpha w-T}{w-T}}{\Delta} d T-\frac{\bar{x}^{\alpha} \Delta}{\Omega \Delta} d \Omega .
$$

Recognizing that $d G\left(a_{l}^{b}\right)=g\left(a_{l}^{b}\right) d a_{l}^{b}$ and $d \bar{x}=\frac{1}{\alpha} \bar{x}^{1-\alpha} d \bar{x}^{\alpha}$ the last two equations can be transformed into the equations (14) and (16) in the main text. 


\section{References}

Allingham, M. G., Sandmo, A. (1972). "Income Tax Evasion: A Theoretical Analysis", Journal of Public Economics, Vol. 1, No. 3-4, pp. 323 - 338.

Amable, B., Gatti, D. (2006). "Labour and Product Market Reforms: A Case for Policy Complementarity", Industrial and Corporate Change, Vol. 15, No. 1, pp. 101 - 122.

Belviso, F. (2003). "Firing Costs and Unemployment: Considering Bankruptcy in a Matching Model", Paper Presented at the 2003 EEA Annual Congress.

Bertola, G. (1994). "Flexibility, Investment, and Growth", Journal of Monetary Economics, Vol. 34, No. 2, pp. $215-238$.

Blanchard, O., Giavazzi, F. (2003). "Macroeconomic Effects of Regulation and Deregulation in Goods and Labor Markets", Quarterly Journal of Economics, Vol. 118, No. 3, pp. 879 907.

Blanchard, O., Landier, A. (2002). "The Perverse Effects of Partial Labour Market Reform: Fixed-term Contracts in France", Economic Journal, Vol. 112, No. 480, pp. F214 - F244. Blanchard, O., Portugal, P. (2001). "What Hides Behind an Unemployment Rate: Comparing Portuguese and U.S. Labor Markets", American Economic Review, Vol. 91, No. 1, pp. $187-207$.

Blanchard, O., Tirole, J. (2004). "The Optimal Design of Unemployment Insurance and Employment Protection", NBER Working Paper 10443.

Boeri, T. (1999). "Enforcement of Employment Security Regulations, On-the-job search and Unemployment Duration", European Economic Review, Vol. 43, No. 1, pp. 65 - 89.

Burda, M. (1991). "Monopolistic Competition, Costs of Adjustment, and the Behavior of European Manufacturing Employment", European Economic Review, Vol. 35, No. 1, pp. $61-79$.

Dixit, A. K., Stiglitz, J. E. (1977). "Monopolistic Competition and Optimum Product Diversity", American Economic Review, Vol. 67, No. 3, pp. 297 - 308.

Ebell, M., Haefke, C. (2003). "Product Market Deregulation and Labor Market Outcomes", IZA Discussion Paper 957.

Galdon-Sanchez, J. E., Güell, M. (2003). "Dismissal Conflicts and Unemployment", European Economic Review, Vol. 47, No. 2, pp. 323 - 335. 
Martin, R., Mongrain, S., Parkinson, S. (2004). "Severance Payment and Unemployment Insurance: A Commitment Issue", Journal of Public Economic Theory, Vol. 6, No. 4, pp. 593 - 606.

Melitz, M. J. (2003). "The Impact of Trade on Intra-industry Reallocations and Aggregate Industry Productivity", Econometrica, Vol. 71, No. 6, pp. 1695 - 1725.

Neugart, M., Storrie, D. (2006). "The Emergence of Temporary Work Agencies", Oxford Economic Papers, Vol. 58, No. 1, pp. 137 - 156.

Samaniego, R. M. (2006). "Do Firing Costs Affect the Incidence of Firm Bankruptcy?", Macroeconomic Dynamics, Vol. 10, No. 4, pp. 467 - 501.

Shavell, S. (1986). "The Judgment Proof Problem", International Review of Law and Economics, Vol. 6, No. 1, pp. $45-58$. 


\section{Employment Protection: The Case of Limited Enforceability Additional Appendix}

\section{Derivation of equation (2)}

The representative consumer maximizes utility $U$ by choosing the consumption quantities $x_{j}$ subject to her budget constraint. The respective Lagrangian is given by

$$
\mathscr{L}=\left[\int_{0}^{\bar{n}} a_{j}\left(x_{j}\right)^{1-\alpha} d j\right]^{\frac{1}{1-\alpha}}-\lambda\left[Y-\int_{0}^{\bar{n}} p_{j} x_{j} d j\right]
$$

with $\lambda$ as the Lagrange multiplier. This yields the first-order conditions for the most preferred consumption bundle

$$
\left[\int_{0}^{\bar{n}} a_{j}\left(x_{j}\right)^{1-\alpha} d j\right]^{\frac{\alpha}{1-\alpha}} a_{i} x_{i}^{-\alpha}+\lambda p_{i}=0
$$

for all $i \in[0, \bar{n}]$. Multiplying equation (A2) with $x_{i}$, integrating the outcome over the varieties of the consumption good and solving for the Lagrange multiplier $\lambda$, one gets

$$
\lambda=-\frac{\left[\int_{0}^{\bar{n}} a_{j}\left(x_{j}\right)^{1-\alpha} d j\right]^{\frac{1}{1-\alpha}}}{Y}
$$

Inserting equation (A3) into equation (A2) one obtains equation (2) in the main text.

\section{Derivation of equation (13)}

From the profit equation, equation (4), and for optimal employment $x^{*}(a)$ the partial derivatives of profits in period 2 with respect to firing costs and with respect to effective output calculate as

$$
\frac{\partial \pi(a)}{\partial T}=-\left[\bar{x}-x^{*}(a)\right]
$$

and

$$
\frac{\partial \pi(a)}{\partial \Omega}=-\frac{a Y}{\Omega^{2}} x^{*}(a)^{1-\alpha} .
$$


Integrating these terms and recognizing the definition of $\Omega$, equation (3), the change in effective output necessary to keep ex-ante expected profits equal to market entry costs is given by ${ }^{13}$

$$
\frac{d \Omega}{d T}=-\frac{\frac{\partial \Pi}{\partial T}}{\frac{\partial \Pi}{\partial \Omega}}=-\frac{\int_{a_{l}^{b}}^{a^{k}}\left[\bar{x}-x^{*}(a)\right] d G(a)}{\frac{1}{\Omega^{2}} \int_{a_{l}^{b}}^{\bar{a}} a x^{*}(a)^{1-\alpha} d G(a)}=-\frac{\int_{a_{l}^{b}}^{a^{k}}\left[\bar{x}-x^{*}(a)\right] d G(a)}{\frac{Y}{\Omega \bar{n}}}
$$

$l=A, B$, yielding equation (13)

\section{The simulation approach}

The outcomes of the simulations are derived in the following way. First, we define an auxiliary variable, $\phi=\frac{\Omega}{Y} \bar{x}^{\alpha}$. Using this definition, we are able to solve for the three variables $a^{k}, a_{l}^{b}$, $l=A, B$, and $\phi$ by use of the two threshold values for the preference parameter and the first-order condition for initial employment, equations (5), (7), and (10). Next, using the definition of $\phi$, the period 2 profit function, equation (8), can be rewritten as

$$
\pi(a)= \begin{cases}0 ; & a \leq a_{l}^{b} \\ \alpha\left(\frac{1-\alpha}{w-T}\right)^{\frac{1-\alpha}{\alpha}}\left(\frac{a Y}{\Omega}\right)^{\frac{1}{\alpha}}-T \bar{x}=\left[\alpha\left(\frac{1-\alpha}{w-T}\right)^{\frac{1-\alpha}{\alpha}}\left(\frac{a}{\phi}\right)^{\frac{1}{\alpha}}-T\right] \bar{x} ; & a_{l}^{b}<a \leq a^{k} \\ \frac{a Y}{\Omega} \bar{x}^{1-\alpha}-w \bar{x}=\left[\frac{a}{\phi}-w\right] \bar{x} ; & a>a^{k} .\end{cases}
$$

$l=A, B$. Accordingly, ex-ante expected profits, defined in equation (9), are linear in initial employment $\bar{x}$, for the calculated values of $a_{l}^{b}, a^{k}$, and $\phi$. Integrating equation $(\mathrm{C} 1)$ and subtracting hiring costs $h \bar{x}$, one can state ex-ante expected profits as a function $\Pi=F \bar{x}$, with $F$ being a constant. From the market entry condition, $\Pi=C$, this allows us to calculate initial employment as $\bar{x}=\frac{C}{F}$ and effective output as $\Omega=\frac{\phi Y}{\bar{x}^{\alpha}}$. Optimal employment in period $2, x^{*}(a)$, then follows from equation (6). Finally, expected employment in period $2, X$, equals

$$
X=\bar{n} \int_{0}^{\bar{a}} x^{*}(a) d G(a)
$$

whereas the number of dismissals, $D$, is given by

$$
D=\bar{n} \bar{x}-X
$$

${ }^{13}$ Note that in equilibrium $\frac{\partial \Pi}{\partial \bar{x}}=\left.\frac{\partial \Pi}{\partial x(a)}\right|_{a_{l}^{b}<a<a^{k}}=\frac{\partial \Pi}{\partial a_{l}^{b}}=\frac{\partial \Pi}{\partial a^{k}}=0, l=A, B$. 


\section{CESifo Working Paper Series}

for full list see www.cesifo-group.org/wp

(address: Poschingerstr. 5, 81679 Munich, Germany, office@cesifo.de)

2285 Axel Dreher and Stefan Voigt, Does Membership in International Organizations Increase Governments' Credibility? Testing the Effects of Delegating Powers, April 2008

2286 Xavier Freixas and Bruno M. Parigi, Lender of Last Resort and Bank Closure Policy, April 2008

2287 Regina Dionisius, Samuel Muehlemann, Harald Pfeifer, Günter Walden, Felix Wenzelmann and Stefan C. Wolter, Cost and Benefit of Apprenticeship Training - A Comparison of Germany and Switzerland, April 2008

2288 Francesco Daveri and Cecilia Jona-Lasinio, Off-Shoring and Productivity Growth in the Italian Manufacturing Industries, April 2008

2289 Mikael Priks, Do Surveillance Cameras Affect Unruly Behavior? A Close Look at Grandstands, April 2008

2290 Marianna Belloc and Daniela Federici, A Two-Country NATREX Model for the Euro/Dollar, April 2008

2291 Nicolas Treich, The Value of a Statistical Life under Ambiguity Aversion, April 2008

2292 J. Atsu Amegashie, Socially-Tolerable Discrimination, April 2008

2293 M. Hashem Pesaran and Andreas Pick, Forecasting Random Walks Under Drift Instability, April 2008

2294 Steven Brakman, Gus Garita, Harry Garretsen and Charles van Marrewijk, Unlocking the Value of Cross-Border Mergers and Acquisitions, May 2008

2295 Eric O’N. Fisher and Kathryn G. Marshall, The Structure of the American Economy, May 2008

2296 Claudia M. Buch and Martin Schlotter, Regional Origins of Employment Volatility: Evidence from German States, May 2008

2297 Helmuth Cremer, Philippe De Donder, Dario Maldonado and Pierre Pestieau, Taxing Sin Goods and Subsidizing Health Care, May 2008

2298 Reinhilde Veugelers and Frederick van der Ploeg, Reforming European Universities: Scope for an Evidence-Based Process, May 2008

2299 Jon H. Fiva and Lars J. Kirkebøen, Does the Housing Market React to New Information on School Quality?, May 2008 
2300 Tina Klautke and Alfons J. Weichenrieder, Interest Income Tax Evasion, the EU Savings Directive, and Capital Market Effects, May 2008

2301 Harald Badinger and Peter Egger, GM Estimation of Higher Order Spatial Autoregressive Processes in Panel Data Error Component Models, May 2008

2302 Jan K. Brueckner, Slot-Based Approaches to Airport Congestion Management, May 2008

2303 Sören Blomquist, Vidar Christiansen and Luca Micheletto, Public Provision of Private Goods and Nondistortionary Marginal Tax Rates, May 2008

2304 Dan Anderberg and Alessandro Balestrino, The Political Economy of Post-Compulsory Education Policy with Endogenous Credit Constraints, May 2008

2305 Tomer Blumkin, Yoram Margalioth and Efraim Sadka, The Role of Stigma in the Design of Welfare Programs, May 2008

2306 Vesa Kanniainen and Paolo M. Panteghini, Tax Neutrality: Illusion or Reality? The Case of Entrepreneurship, May 2008

2307 Thomas Dohmen, Armin Falk, David Huffman and Uwe Sunde, The Intergenerational Transmission of Risk and Trust Attitudes, May 2008

2308 Guglielmo Maria Caporale and Mario Cerrato, Using Chebyshev Polynomials to Approximate Partial Differential Equations, May 2008

2309 Peter Egger and Doina Maria Radulescu, Labour Taxation and Foreign Direct Investment, May 2008

2310 Laurent Linnemer, Dissipative Advertising Signals Quality even without Repeat Purchases, May 2008

2311 Jordi Jofre-Monseny and Albert Solé-Ollé, Which Communities should be afraid of Mobility? The Effects of Agglomeration Economies on the Sensitivity of Firm Location to Local Taxes, May 2008

2312 Andreas Haufler and Ferdinand Mittermaier, Unionisation Triggers Tax Incentives to Attract Foreign Direct Investment, May 2008

2313 Ronel Elul and Piero Gottardi, Bankruptcy: Is it enough to Forgive or must we also Forget?, May 2008

2314 Andreas Irmen and Johanna Kuehnel, Productive Government Expenditure and Economic Growth, May 2008

2315 Beate Henschel, Carsten Pohl and Marcel Thum, Demographic Change and Regional Labour Markets: The Case of Eastern Germany, May 2008 
2316 Gabriel Felbermayr, Wido Geis and Wilhelm Kohler, Restrictive Immigration Policy in Germany: Pains and Gains Foregone?, May 2008

2317 Michael Hofmann, Gerhard Kempkes and Helmut Seitz, Demographic Change and Public Sector Budgets in a Federal System, May 2008

2318 Paul De Grauwe, Macroeconomic Modeling when Agents are Imperfectly Informed, June 2008

2319 Johann K. Brunner and Susanne Pech, Optimum Taxation of Inheritances, June 2008

2320 Thomas Eichner and Marco Runkel, Corporate Income Taxation of Multinationals in a General Equilibrium Model, June 2008

2321 Rainald Borck and Matthias Wrede, Subsidies for Intracity and Intercity Commuting, June 2008

2322 Patricia Apps and Ray Rees, Testing the Pareto Efficiency of Household Resource Allocations, June 2008

2323 Amihai Glazer, Vesa Kanniainen and Panu Poutvaara, Firms' Ethics, Consumer Boycotts, and Signalling, June 2008

2324 Claudia M. Buch, Jörg Döpke and Kerstin Stahn, Great Moderation at the Firm Level? Unconditional vs. Conditional Output Volatility, June 2008

2325 Helmuth Cremer, Philippe De Donder, Dario Maldonado and Pierre Pestieau, Forced Saving, Redistribution and Nonlinear Social Security Schemes, June 2008

2326 M. Hashem Pesaran and Paolo Zaffaroni, Optimal Asset Allocation with Factor Models for Large Portfolios, June 2008

2327 Harald Badinger and Peter Egger, Horizontal versus Vertical Interdependence in Multinational Activity, June 2008

2328 Jan K. Brueckner and Harris Selod, A Theory of Urban Squatting and Land-Tenure Formalization in Developing Countries, June 2008

2329 Paolo M. Panteghini, Corporate Debt, Hybrid Securities and the Effective Tax Rate, June 2008

2330 Guglielmo Maria Caporale, Juncal Cuñado and Luis A. Gil-Alana, Modelling Long-Run Trends and Cycles in Financial Time Series Data, June 2008

2331 Avi Ben-Bassat and Momi Dahan, Social Identity and Voter Turnout, June 2008

2332 Martin R. West and Ludger Wößmann, "Every Catholic Child in a Catholic School”: Historical Resistance to State Schooling, Contemporary Private Competition, and Student Achievement across Countries, June 2008 
2333 Erkki Koskela and Panu Poutvaara, Outsourcing and Labor Taxation in Dual Labor Markets, June 2008

2334 Philippe Choné and Laurent Linnemer, Optimal Litigation Strategies with Signaling and Screening, June 2008

2335 Albert Solé-Ollé and Pilar Sorribas-Navarro, Does Partisan Alignment Affect the Electoral Reward of Intergovernmental Transfers?, June 2008

2336 Antonio Cabrales and Piero Gottardi, Markets for Information: Of Inefficient Firewalls and Efficient Monopolies, June 2008

2337 Sumon Majumdar and Sharun W. Mukand, The Leader as Catalyst - on Leadership and the Mechanics of Institutional Change, June 2008

2338 Ulrich Hange, Tax Competition, Elastic Labor Supply, and Growth, June 2008

2339 Guy Laroque and Bernard Salanié, Does Fertility Respond to Financial Incentives?, June 2008

2340 Adriano Paggiaro, Enrico Rettore and Ugo Trivellato, The Effect of Extending the Duration of Eligibility in an Italian Labour Market Programme for Dismissed Workers, June 2008

2341 Helmut Seitz, Minimum Standards, Fixed Costs and Taxing Autonomy of Subnational Governments, June 2008

2342 Robert S. Chirinko, Leo de Haan and Elmer Sterken, Asset Price Shocks, Real Expenditures, and Financial Structure: A Multi-Country Analysis, July 2008

2343 Wolfgang Leininger, Evolutionarily Stable Preferences in Contests, July 2008

2344 Hartmut Egger and Udo Kreickemeier, Fairness, Trade, and Inequality, July 2008

2345 Ngo Van Long and Bodhisattva Sengupta, Yardstick Competition, Corruption, and Electoral Incentives, July 2008

2346 Florian Baumann, Employment Protection: The Case of Limited Enforceability, July 2008 